\title{
Preface to Second Edition
}

The second, revised edition of Key Concepts in Literary Theory has been expanded in two of its three sections, 'Concepts and Terms', and 'Chronology of Critical Thinkers, with Bibliographies'. With the intention of providing a more comprehensive coverage, and so filling in what, in retrospect, now appear obvious omissions, more than eighty terms and their definitions have been added to the first part of the volume. It is hoped that the changes provide additional usefulness to the reader, while, equally, the volume has retained the accessibility, ease of reference, and 'portability' of the first volume. Of the inclusions, the majority are drawn from psychoanalysis, reflecting the continued and sustained interest in this particular approach to literary studies, even while the fortunes of other discourses appear to have waned somewhat. Of the remaining other inclusions, several are 'formalist' in nature, concerned with grammatical, linguistic, and rhetorical terminology that has found a renewed currency in particular areas of discursively focused literary theory. Finally, with regard to inclusion, those concepts or terms not covered obviously by a psychoanalytic or linguistic rubric are drawn from historically or sociologically inflected or influenced critical modes. In the third part, the chronology, around forty additional critics, philosophers, and historians have been added. To the existing entries, a couple of major publications have been included, which appeared subsequent to the original publication of Key Concepts in 2002. As with the first edition of Key Concepts, in most cases and whenever possible, I have sought to give in-print paperback editions of as many of the publications as possible. The other changes made to the chronology are, sadly, death dates for several of the thinkers listed there.

As ever, once more, and no less sincerely, I would like to thank Jackie Jones at Edinburgh University Press. I would also like to take the opportunity to thank Ruth Robbins and Ken Womack for their work on the first 
edition. Any errors or infelicities, Austinian or otherwise, in the current edition are entirely my own.

Julian Wolfreys, London and Los Angeles July 2005 